\title{
Cinema e Ensino de História: propaganda e crítica em outubro e o triunfo da vontade.
}

Marcos SILVA ${ }^{1}$

\section{RESUMO}

Fste artigo discute os filmes Outubro (1927), de Serguei Eisenstein e Grigory Alexandrov, e 0 triunfo da vontade (1935), de Leni Riefenstahl. 0 texto destaca diferentes ligações entre cada filme e o regime político do país onde foi produzido. Eisenstein e Alexandrov comemoram a Revolução de 1917 mas preservam tensões narrativas sobre significados dos ídolos para a política. Riefenstahl reafirma ideais nazistas e define seu filme como obra de propaganda. Os dois filmes podem ajudar nos debates do Ensino de História sobre o conceito de Totalitarismo.

Palavras-chave: Outubro (o filme)- 0 triunfo da vontade - Serguei Eisenstein e Grigory Alexandrov - Leni Riefenstahl - Cinema e Ensino de História.

Os filmes Outubro, de Serguei Eisenstein e Grigory Alexandrov ${ }^{2}$, e 0 triunfo da vontade, de Leni Riefenstahl 3 , foram encomendados aos respectivos diretores pelos governos da URSS stalinista e da Alemanha nazista. Essa circunstância é um forte incentivo para o espectador se lembrar das equiparações entre Stalinismo e Nazismo, consolidadas, dentre outros autores, pela filósofa Hannah Arendt(1989) ${ }^{4}$. E para desdobrá-la numa equiparação entre os diretores dos dois filmes.

Comentarei cada um deles, realçando suas peculiaridades históricas e os alcances que cada diretor conseguiu estabelecer através de seu trabalho com a linguagem cinematográfica. Dessa forma, procurarei verificar a adequação daquela

\footnotetext{
Professor titular de Metodologia da História na FFLCH/USP. marcossilva.usp@uol.com.br .

Ver ficha técnica no final deste texto.

Ver ficha técnicá no final deste texto.

- Ima dura crítica a conceito de Totalitarismo (particularmente, sobre sua imagem de não-Liberalismo, como se o último conceito fosse um ideal de política), que não cita Arendt, éfeita no ensaio: CHASIN, J. "Sobre o conceito de 'Totalitarismo". Ensaios Ad Hominem. São Paulo: Estudos e Edições Ad Hominem, 1: 79/89, 2000.
} 
suposta identidade totalitária, bem como as relaçães de Eisenstein/Alexandrov e Riefenstah com política, propaganda e crítica. Nessa perspectiva, as duas obras podem participar da operação didática na História como elementos na discussão de uma problemática de conhecimento: o conceito de totalitarismo na discussão dos embates políticos do século XX5.

Outubro possui elementos que o identificam facilmente ao gênero "cinema histórico": seu tema é a Revolução Russa, de 1917, grande acontecimento da História do século XX; e ele foi encomendado para comemorar os dez anos do evento, constituindo uma memória intencional sobre o tema.

Vale a pena explorar-lhe outros níveis de historicidade, principalmente a assustadora materialidade cinematográfica ${ }^{6}$. Como noutros filmes de Eisenstein, o trabalho com a linguagem do cinema é meticuloso, ousado a ponto de alguns de seus resultados terem se transformado em referências canônicas para cineastas e fotógrafos posteriores. 0 pavão com aparência metalizada, na sala de trabalho de Alexandre Kerensky, parece ter ressurgido na coruja replicante que voa na sala de Tyrell, o empresário de Blade Runner (filme de Ridley Scott) 7 , que projetara os robôs humanóides, tornados humanos (até mais que os humanos) através da própria experiência. As foices e os fuzis, erguidos com orgulho por soldados e camponeses revolucionários, foram reapropriados por Sebastião Salgado, em suas tantas fotografias de camponeses(SALGADO, 1997).

Essas evidências nos lembram, de imediato, que estamos diante de um clássico, no mesmo sentido em que os movimentos de cabelos e o strip-tease da luva longa, por Rita Hayworth, transformaram o filme Gilda, de Charles Vidor, num clássico - todo comercial de shampoo e todo strip-tease são tributários de Gilda; ou o box de chuveiro, no grande Psicose, de Alfred Hitchocock, grande referência para filmes que exploram tensão e suspense ${ }^{8}$. Mas também nos convidam a

\footnotetext{
Abordo as relações entre conhecimento histórico em geral, ensino de História e filmes no texto: SILVA, Marcos. "História, filmes e ensino: Desavir-se, reaver-se", in: NOVOA, Jorge, FRESSATO, Soleni e FEIGEISON, Kristian (Orgs.). Cinematógrafo - Um olhar sobre a História. São Paulo/Salvador: EDUNESP/EDUFBA, 2009, p 147/157.

" Exemplos da teorização dessa materialidade por Eisenstein estão expostos no livro: EISENSTEIN, Serguei. Reflexões de um cineasta. Rio de Janeiro: Zahar, 1969.

Ver ficha técnica no final deste texto

s Ver fichas técnicas no final deste texto.
} 
pensar sobre a capacidade que o cinema tem de criar seus fatos, ultrapassando em muito uma análise de discursos supostamente paralelos, e da fidelidade ou não na relação entre eles: no caso, o do filme Outubro e o do acontecimento anterior, "Revolução de 1917", tematizado por seus diretores.

Tal paralelismo finda desprezando o filme como acontecimento. Do ponto de vista da História, o acontecimento fílmico remete ao universo da Arte e ao universo da Memória. o filme é um fazer de Memória Artística, a ser debatido preliminarmente, por historiadores, nesses níveis, mesmo que uma das legendas iniciais de Outubro reitere sua condição de "testemunha ocular e precisa do começo do nosso Estado Socialista".

É preciso estar atento à opção por "Estado", e não "Sociedade", nessa declaração. Quem optou por Estado como lugar da Revolução foram Eisenstein e Alexandrov? Foi a hegemonia então vigente naquela Sociedade? A existência de diferentes versões de Outubro, em circulação internacional, sugere que Censura e órgãos semelhantes interferiram largamente nas finalizações do filme, independentemente da vontade de seus diretores. E que muito do que esses diretores quiseram mostrar escapou da censura.

Mais que testemunha ocular de qualquer coisa, Outubro é um artefato artístico de 1927, ativo agente de uma memória em construção e em disputa sobre a Revolução de 1917. E nessa construção e disputa, avulta a dimensão excepcional atribuída a Vladimir Lênin (morto em 1924), como personagem da narrativa e autor de referências em epígrafes e outros trechos textuais do filme.

Essa dimensão pode ser associada à relação de forças na política soviética daquele momento: Lênin morto, a batalha entre Josef Stálin e Leon Trótsky bastante adiantada - expulsão do último do PCURSS em novembro de 1927, seu exílio, em Alma-Ata, em 1928, e expulsão, da URSS, em 1929 -, a estrutura dos sovietes sob pleno controle de um Estado com partido único. Mas o filme não se reduz a ela.

Outubro se inicia com belíssima cena: uma mulher começa a amarrar, com cordas, gigantesca estátua do czar Alexandre III; um homem escala o mesmo monumento, usando uma escada, complementando aquele trabalho de amarrar junto com outros homens; um plano nos mostra o monumento preso por incontáveis cordas e a estátua começa a despencar, sob a ação da multidão.

"Consta da ficha técnica de Outubro que o livro-reportagem 10 dias que abalaram o mundo, de John Reed, foi seiu ponto de partida textual. REED, John. 10 dias que abalaram o mundo. São Paulo: Global, 1978. 
É possível identificar uma crítica aos diferentes ídolos na História, nessa passagem e depois. Sim, a cena representa a derrubada do Czarismo, até de forma literal. Mas também faz parte de uma profunda crítica aos ídolos, reiterada ao longo do filme - Lênin estava virando um imenso ídolo, inclusive embalsamado (posteriormente, a canção "Rancho da goiabada", de João Bosco e Aldir Blanc, falaria em "faraós embalsamados"), e o filme participava desse processo -, de maneira muito tensa, todavia. Se Eisenstein foi transformado, depois, em ídolo, seu cinema não visava a isso.

Outubro narra a revolução, traça periodizações desse processo, aponta acontecimentos e personagens - no último caso, um Lênin clarividente, um Trótsky vacilante e meio cabisbaixo, um Kerensky sempre ridículo... Mas revela olhos muito atentos para a presença da multidão nos acontecimentos, para sentimentos necessários à formação de um processo humano de vontade de revolução. E faz isso apresentando os machos e as fêmeas, os jovens e os velhos, figuras de diferentes regiões do Império russo.

As imagens que mostram pela primeira vez, nesse filme, os soldados na Grande Guerra enfatizam a pluralidade etária desses homens (uns enrugados, outros quase crianças), um profundo afeto entre eles, realçado por legendas como "Irmão" e "Amigo", uma desconcertante alegria, em meio a sofrimento e cansaço. E essa confraternização se expressa em momentos dedicados a comer e beber, atos básicos de sobrevivência. Ou nos toques entre corpos e nas trocas de adereços - capacete militar por boina é un exemplo.

A contrapartida dessa Rússia de afetos é o universo do Governo Provisório, marcado por luxo, formalidade cortesã, funcionários que se curvam diante dos superiores, magníficos pisos e outros adereços arquitetônicos e decorativos ostensivamente luxuosos. Ee essa Rússia do Governo Provisório, contraposta à pobreza e à fome dos homens e mulheres comuns, que aparece como responsável pela continuidade do que existia antes - guerra e carências. 0 Governo Provisório é um forte atestado de que a Contra-Revolução estava vencendo.

Eisenstein e Alexandrov desenvolvem um belo trabalho de montagem cinematográfica - não fosse o primeiro um dos inventores da linguagem do filme apoiada em tal procedimento -, apelando para composições de expressivos quadros visuais, formados por rostos ou diferentes objetos, como baionetas de fuzis que se espetam no chão e, depois, cálices de cristal, pratarias, relógios. Os dois diretores trabalham com 
imagens num ritmo musical, mesclado ao contraponto entre realidades, experiências e projetos de diferentes sujeitos: os pobres com vontade de futuro, versus os ricos, violentos e destrutivos, que espezinhavam, até literalmente, os outros.

É nesse contexto narrativo que o filme constrói uma de suas mais brilhantes imagens. A repressão do Governo Provisório a manifestações populares inclui isolar bairros de moradia desse último setor da população, suspendendo pontes movediças. Em meio a essa operação, surge a figura de um impressionante cavalo, morto, pendurado no espaço que se abre na ponte, até cair na água, bem como aparecem revolucionários agredidos, derrubados, sendo um deles (provavelmente, uma mulher) dotado de longos cabelos, que escorrem no vão da ponte, enquanto o corpo humano cai, numa rima visual com a crina daquele animal. No final dessa sequiência, aparece uma escultura com aspecto de egípcia antiga, evocando poder e autoridade. São, todavia, poder e autoridade do passado, e até mutilados. Trata-se de tema recorrente no filme - a crítica de imagens mais ou menos sagradas, expondo sua patética finitude de ídolos.

Uma função visual assumida por Outubro é exatamente essa radical crítica das imagens supostamente indiscutíveis (sagradas ou cívicas), donde a sucessão de medalhas, comendas, dragonas, esculturas de diferentes civilizações. E em meio a esses símbolos de diversos poderes, a gigantesca estátua de Alexandre III, cuja demolição marcara a abertura do filme, se recompõe, para em seguida ser sucedida pelas imagens de alguns daqueles outros ídolos sendo despedaçados, como se a História fosse uma sucessão de ídolos erguidos e derrubados, reerguidos e re-derrubados.

A revolução, nesse filme, é construída como obra coletiva, que se realiza quando as armas estão nas mãos do povo, contingente que inclui jovens e idosos, homens e mulheres. 0 trabalho de formar quadros visuais com diferentes objetos incluiu armas e impressos (possivelmente, panfletos, sem esquecer dos exemplares do jornal Pravda, atirados no rio pelos contra-revolucionários), salientando a amplitude grupal que qualquer revolução exige. E os militares de baixa patente assumem uma proporção de extremo significado no processo, expressa tanto visualmente, na presença de tantos soldados e marinheiros em cena, quanto no refrão reproduzido: "Proletariado, aprenda a usar seu rifle."

o filme materializa, no plano visual, o caráter de revolução operária, camponesa e de soldados, apresentando a ação política e militar desses grupos. Em meio à 
narrativa épica da revolução, cabe registrar o apelo à retórica cômica, especialmente, na caracterização de Kerensky, ridiculamente contraposto à grandiosidade de Napoleão, situação que culmina na apresentação paralela daquele personagem e de um pavão com aspecto metalizado, que parece um objeto inanimado para, em seguida, assumir aspecto de um ser vivo. Noutro momento de delírio atribuído a Kerensky, o narrador do filme pergunta (em legenda) se aquele Alexandre seria o novo czar, Alexandre IV. Quando Kerensky brinca com luxuosa peça de cristal, coroando-a, o desdobramento dessa imagem é uma tropa de soldados de brinquedo.

Os quadros de objetos, reiteradamente montados como recurso narrativo do filme, encontram um correspondente com aparência de não ser montado, no momento em que os revolucionários invadem o Palácio de Inverno: a profusão luxuosa de quinquilharias nos aposentos da Imperatriz e o excesso de garrafas na adegá. Não está em jogo a pré-existência daqueles quadros: eles são fatos do filme, fatos constitutivos de uma memória reflexiva sobre seu tema; e exigem, do espectador, o ato interpretativo para que o trabalho de montagem não se confunda com um jogo formal. Evocando o recurso psicanalítico da livre associação, a narrativa convida quem a acompanha a tecer articulações entre tantos objetos e imagens, em busca de seus nexos para a compreensão daquela realidade.

o filme de Eisenstein e Alexandrov se encerra como nova epígrafe de Lênin, reiterando a criação do Estado socialista proletário. Anarração principal que Outubro tece é sobre o mundo anterior a essa criação, quando o que estava em jogo não era somente o Estado, e sim a Sociedade tomando seu destino nas próprias mãos.

o filme é fiel aos fatos? Sim, no que se refere a seus próprios fatos

Feito por encomenda, Outubro faz pensar sobre revoluções em potênciaalém daquela que o Estado procurava monopolizar -, que a linguagem artística teimava em evocar. Na medida em que a revolução se desmontava (desde o início dos anos 20! Proibição de facções no partido, depois da oposição de esquerda, visão depreciativa das artes experimentais, transformação do mundo socialista em gestão do Estado), tal homologia cinematográfica enfrentou mais e mais barreiras para sobreviver - a extrema violência stalinista, a política estética do "Realismo socialista" -, donde as crescentes dificuldades que Eisenstein sofreu, até 0 final da vida, para fazer novos filmes ${ }^{10}$.

(1) Informações sobre essas dificuldades são expostas em: MACHADO), Arlindo. Serguei M. Eisenstein. São Paulo: Brasiliense, 1982 (Encanto Radical - 8). 
É doloroso pensar nos belos filmes que esse e outros cineastas não fizeram por mera insegurança do Estado. Mas ao menos cabe o consolo de que não estamos diante da Ideologia do regime.

Outubro não é Stalinismo, nem Realismo socialista, e sim um Triunfo da Poesia. A memória principal que dele resulta é a da capacidade interpretativa da Arte sobre o mundo do Socialismo que se tentava construir, e que se destruía em nome dele mesmo.

A diretora Leni Riefenstahl representa um desafio para a visão crítica de filmes: ela se constitui num evidente talento, é dotada de cultura cinematográfica, capacidade inventiva e inovadora em seu campo de linguagem... a serviço do Nazismo. Sobrevivendo longamente ao regime (nasceu em 1902 e morreu em 2003!), a cineasta sempre negou ter sido nazista, alegando que não se filiou ao partido e também que, se vivesse na URSS ou nos EEUU, faria filmes nesses outros regimes políticos, porque Cinema era sua profissão. Supunha, portanto, certa indiferença da produção artística em relação ao campo político da experiência humana.

Jamais saberemos com exatidão sobre convicções íntimas de Riefenstahl nem de ninguém. Seu trabalho concreto de direção no documentário 0 triunfo da vontude, que apresenta o Quarto Congresso do Partido Nazista (1934), contudo, é mais que coerente com a ideologia filmada, é um exemplo privilegiado dela, que Leni Riefenstahl assumiu enquanto convicção pública, em elegante estilo cinematográfico. Certamente, alguns tópicos do Nazismo não aparecem de forma evidente na obra, em particular, a questão de como tratar quem era julgado inferior aos arianos - judeus, eslavos, ciganos, homossexuais, deficientes físicos etc embora um dos muitos discursos de Hitler ali apresentados fale sobre a força da nação unificada (quer dizer: homogênea, racialmente pura). Mas a magnificência dos auto-designados superiores é reafirmada a cada momento, e num estilo impressionante de exibir poder com beleza visual. Ao invés de indiferença da Arte em relação à Política, Leni exemplifica a perfeita sintonia entre o primeiro fazer e a face hegemônica do segundo: a exibição reforça o que é exibido.

0 título do filme foi sugerido pelo próprio Adolf Hitler, inspirado em livro de Friedrich Nietzsche (batizado por terceiros porque o filósofo jáse encontrava doente quando escreveu os aforismos que o compõem) como Vontade de potência. Adolf mesmo escolhera a diretora para a tarefa de realizar o documentário sobre aquele encontro partidário e Leni dispôs de importantes recursos e apoios na realização 
de sua obra. Nunca essa escolha recairia sobre um diretor de posturas políticas contrárias ao Nazismo, ou mesmo independentes em relação a ele!

Pode parecer excessivo supor que Riefenstahl projetou o conjunto de atividades do evento em função da filmagem - ela nem tinha poder para tanto -, mas não é abuso pensar que a diretora participou muito intensamente de seu planejamento conjunto, estudou-o detidamente, garantindo a extrema precisão de tomadas de câmera (que, às vezes, assumiam o ponto de vista de Hitler, num avião ou automóvel, quando não se situavam em meio às tropas em desfile ou a outros grupos), para a posterior montagem do documentário. Nesse sentido, 0 congresso exemplifica a prática nazista de conceber a Política como obra de Arte (espetáculo) ${ }^{11}$ e o documentário de Leni Riefenstahl garantiu o registro desse fazer, constituindo-se ele mesmo noutra criação artística. A minúcia do estudo que Riefenstahl e sua equipe fizeram das cerimônias se manifesta, por exemplo, na filmagem de um batalhão a partir de um ângulo superior à cena, permitindo ver o grupo humano e a sombra projetada de seus braços em saudação nazista, numa multiplicidade de planos e materialidades.

A precisão de tomadasé um importante traço estilístico de Riefenstahl como diretora, expresso através de movimentos de câmera geométricos e contínuos, enquadramentos monumentais e luminosidade teatralmente muito definida, que constituem uma espécie de anti-Expressionismo de Cinema, uma ostensiva resposta ao universo de tensões que marcara muitos filmes da República de Weimar (1918/1933), com seus cenários labirínticos e extremos contrastes de luz e sombra $^{12}$. E, no caso de 0 triunfo da vontade, a toda hora rola uma suástica ${ }^{13}$.

Tal onipresença do símbolo é muito significativa: era preciso, do ponto de vista do Nazismo, lembrar reiteradamente quem é que mandava ali, como se fora dele não houvesse escapatória. E o estilo de Riefenstahl participa dessa tarefa, com muita eficiência, ao conceber imagens que desejam ser perfeitas, em sequiências de montagem sem tensão, como se tudo decorresse de uma ne-

\footnotetext{
${ }^{11}$ Esse tema aparece no clássico ensaio: BENJAYIN, Walter. "A obra de arte na era de sua reprodutibilidade técnica", in: Magia e técnica, arte e política. Tradução de Sérgio Paulo Rouanet. São Paulo: Brasiliense, 1994, p 165/196.

13 Reflexões sobre o Expressionismo cinematográfico alemão diante do Nazismo são desenvolvidas em: KRACAuteR, Siegfried. De Caligari a Hitler: uma história psicológica do cinema alemão. Rio de Janeiro: Jorge Zahar, 1988.

13 Parafraseio um verso de Paulinho da Viola: "A toda hora rola uma História", verso da canção com o mesmo título. Evidentemente, o sambista não tem nenhuma relação com o universo nazista!
} 
cessidade do real. Trata-se de um Cinema admirativo, que reitera o que mostra como um permanente ponto final e de exclamação! Essa construtora de imagens parece colocar o espectador na situação de eterno emissor de submissos "ohs!" de deslumbramento e adesão. Se as interjeições fossem dirigidas ao Socialismo soviético ou ao Capitalismo estadunidense, o limite seria o mesmo: uma Arte sem. problematizações do mundo, uma Arte de apoio ao mundo tal qual se oferece; o exato contrário da Literatura como anti-ideologia, conforme concebida por Roland Barthes (BARTHES, 1980).

A narração de 0 triunfo da vontade enfatiza uma periodização histórica a partir da derrota na Primeira Guerra Mundial, marco de crise para a Alemanha, e da consolidação do Nazismo, definido como "Renascimento alemão". Suas cenas iniciais apresentam belos planos de nuvens, índices de altura (vôo de avião) e grandeza do espaço e da visão, além de modernidade de temas e personagens. Logo, o espectador entende que aquele veículo transporta Hitler para as cerimônias do Dia do Partido, em Nuremberg (5 de setembro de 1934). Literalmente, o líder desce dos céus para seu povo ${ }^{14}$.

O clima da chegada de Hitler é de eufórica alegria, com jovens e crianças aplaudindo e acenando, um público gigantesco em entusiástica recepção. 0 filme garante um ritmo narrativo dinâmico, com travelings feitos a partir de automóvel em movimento e uma montagem que procura garantir clima de agilidade. As cenas apelam para ícones sentimentais, como uma criança que entrega flores a Adolf ou um gato que se instala numa janela, dando um tom de intimidade familiar a tudo, até trazendo famílias inteiras que observam os acontecimentos de suas janelas.

Mas essa intimidade tem por permanente contraponto a dimensão gigantesca de espaços (ruas, estádios), grupos humanos e adereços (bandeiras, estandartes). 0 sentimento de grandeza se expressa, ainda, na presença de batalhões e mais batalhões, geometricamente dispostos, multidão que parece um formigueiro bem planejado.

Tal impressão visual de serem insetos submetidos à disciplina matemática se reforça na primeira apresentação do Acampamento da Juventude, com tendas

\footnotetext{
14 Marilena Chauí fez interessantes comentários sobre a campanha eleitoral de Fernando Collor de Mello, em 1989, incluindo cenas de chegada aérea a locais desse trajeto. Embora o filme de Riefenstahl não seja citado por Chauí, a semelhança de procedimentos narrativos entre aquelas cenas e o filme alemão é grande. CHAUÍ, Marilena. Comentários em "Debate com o público", in: CASTORIADIS, Comelius. A criação histórica: o projeto da autonomia. Porto Alegre : Artes e Ofícios, 1992, p 40/51 (trecho evocado: p 47/51).
} 
repetidas. $\Lambda$ maior proximidade em relação a esse grupo traz jovens (alguns quase crianças) sem camisa, expondo músculos, fazendo barbas, penteando-se ou lavando-se uns aos outros (um dos rapazes esfrega sabão nas costas de outro), clima de camaradagem masculina que coloca esses virtuais soldados num universo ideal de confraternização, como se não fossem candidatos à morte para dali a pouco. Esse fragmento do filme enfatiza beleza e alegria dos moços, imagem contagiante do Nazismo dotado de tônus e futuro.

Outro agrupamento apresentado com grande beleza é o conjunto de camponeses (diferentes regiões germânicas) de ambos os sexos e em roupas tradicionais, conduzindo ou usando alegorias com frutos, espetáculo de uma natureza prodigiosa e de uma diversidade submetida à autoridade do Führer.

Um terceiro grupo, somente masculino, que aparece no filme em submissão à autoridade hitlerista é a Frente de Trabalho, com batalhões que empunham pás ou picaretas. Adolf assume aspecto paternal em relação a esses homens, enfatizando o fim do conflito de classes na Alemanha da suástica, no mundo do trabalho militarizado.

Anarrativa de O triunfo da vontade é intensamente concentrada na figura de Adolf Hitler. Num segundo plano, aparecem lideranças nazistas importantes, como Martin Bormann, Joseph Goebbels, Hermann Goering., Rudolf Hess. No último lugar, vem a multidão: desindividualizada, feliz, submissa. A submissão de todos à autoridade do primeiro se confunde com os interesses da Alemanha, como se o país e o líder máximo fossem uma só coisa. Exaltar a Alemanha se desdobra em convidar à paciência, ao trabalho incansável, à obediência.

Adescida inicial de Hitler vindo do céu sugere uma identificação entre o líder e uma divindade, questão reforçada pelo clima operístico wagneriano de várias cerimônias do congresso, que o filme registra meticulosamente, incluindo seus efeitos de iluminação e coreografia. Juramentos prestados a Hitler, em uníssono, aproximam-se de rezas e estão articulados ao caráter automático de comportamentos como o "passo de ganso", nos desfiles de tropas. Num filme expressionista como Metropolis, de Fritz Lang (1927), o risco da perda do humano é considerado uma ameaça terrível. Em 0 triunfo da vontade, a automatização das pessoas figura como grande conquista da sociedade disciplinada ${ }^{15}$.

\footnotetext{
${ }^{15}$ Esse teor reiterativo do filme em relação a seu campo temático evidencia o caráter de propaganda de que se reveste, sem espaço para potencialidades, dúvidas e eventuais críticas. Sobre a propaganda e o cinema no Nazismo, ver: DIEHL, Paula. Propaganda e persuasão na Alemanha nazista. São Paulo: Annablume, 1996. GIESEN, Rolf. Nazi propaganda films: a history and filmography. Jefferson: Mckarland, 2003.
} 
As multidões humanas se desdobram em oceanos de braços, dorsos e adereços, em especial, bandeiras, estandartes e similares, além de tochas.

No encerramento do Quarto Congresso do Partido Nazista, em meio à ênfase na grandiosidade do ambiente e da multidão reunida, há um absoluto cuidado do filme em relação ão discurso de Hitler. Visualmente, em mais de um momento, o enquadramento de filmagem situou Hitler num canto do quadro com uma imagem de águia noutro canto, espécie de rima visual entre grandezas simbólicas. 0 crescendo vocal do discurso é minuciosamente apresentado, evidenciando o absoluto domínio retórico do orador (ritmo, volume, dramaticidade). Hitler atua como uma espécie de regente de seu público, que aplaude disciplinadamente nas pausas de sua fala. Após o encerramento do discurso, a entrada em cena de Rudolf Hess, que culmina num convite ao retorno de Hitler, sugere momento meticulosamente coreografado. E as tomadas de cena a partir dos fundos do vasto salão colocam para o espectador do filme uma perspectiva de virtual presença naquele espaço e naquele momento.

Riefenstahl negou, até morrer, ter sido nazista, e apontava como provas disso a presença de múltiplas belezas raciais no filme Olympia (sobre as Olimpíadas em Berlim, de 1936, com a impagável cena da vitória do corredor negro estadunidense Jesse Owens na prova de 100 metros - ele ganhou outras três medalhas de ouro -, produzindo reação irada em Hitler), mais seu posterior projeto inacabado sobre os africanos Nuba (também conhecidos como Nuer), do Sudão, que resultou em longa série de bonitas fotografias, publicadas em livros nos anos 70 .

Certamente, esses exemplos assumem de maneira integral belezas nãoarianas - em olympia, junto com atletas negros e brancos, aparecem amarelos, todos com corpos bonitos e ágeis. Pode ser também uma repetição da estratégia presente em 0 triunfo da vontade: os tópicos explicitamente racistas do Nazismo não figuram de forma evidente na obra. Isso não exime outros filmes de Leni Riefenstahl de serem nazistas, talvez demonstre que havia diversidade sobre doutrina racial no interior do Nazismo; ou ateste o triunfo dessa diversidade depois que aquele regime deixou de existir, no caso do projeto sobre os Nuba, apesar de um ritmo perturbadoramente lento para a efetivação desse novo momento em escala internacional: demorado fim do apartheid no sul dos EEUU (1963!), ainda mais tardia superação do mesmo problema na Rodésia (1980!) e na África do Sul (1991!). E as "limpezas étnicas" na ex-Iugoslávia (1995!) e noutras partes do 
mundo - inclusive as humilhações físicas que soldados americanos impuseram a prisioneiros de guerra no Oriente Próximo e na prisão de Guantánamo - demonstram, assustadoramente, que práticas exterministas da diferença étnica sobrevivem até hoje.

É incômodo, para quem não comunga do universo ideológico nazista (espero que a maioria dos espectadores atuais!), reconhecer o enorme talento de Riefenstahl. Sim, havia nazistas até brilhantes - no Cinema e noutras áreas de atuação! Que foram nazistas, destruindo os outros, autodestrutivamente. 0 talento de Leni não elimina esse traço de sua produção artística; diferentemente de um Serguei Eisenstein, que soube problematizar os descaminhos da Revolução Russa, no filme Outubro (e noutros grandes filmes), e enfrentou, depois, as maiores dificuldades para filmar na URSS; ou de um Orson Welles, que debateu brilhantemente o espaço público de Imprensa e Cinema norte-americanos na obra-prima Cidadão Kane (e outros temas, noutros filmes), e teve sua carreira de diretor, praticamente, impossibilitada nos EEUU. Eisenstein e Welles não fizeram propaganda (alma do negócio, negócio sem alma), e atingiram níveis artísticos os mais elevados.

Riefenstahl também enfrentou grandes dificuldades para fazer filmes depois que o Nazismo acabou. Era muito difícil convencer quem derrotou o regime de que ela não contribuíra intensamente para a imagem grandiosa que, um dia, o Nazismo projetou de si, como propaganda.

Parece o clássico samba de Noel Rosa "Cor de cinza":

"A luva éo documento

de pelica e bem cinzento

que lembra quem me esqueceu."

O triunfo da vontade é o documento, de celulóide e em branco e preto, que lembra o que Leni Riefenstahl queria ver esquecido, sem o conseguir.

Certamente, nem todo o Socialismo soviético está contido no filme de Eisenstein/Alexandrov, assim como nem todo o Nazismo está exposto no filme de Riefenstahl. A prova da força crítica da arte, no caso de Outubro, reside exatamente na capacidade de apresentar tensões naquele universo político. Nesse sentido, uma parcela do Socialismo soviético - a produção artística - conseguiu se manter, durante algum tempo, capaz de enfrentar as barreiras ideológicas stalinistas. 0 mesmo não pode ser dito de 0 triunfo da vontade: malgrado seus evidentes 
méritos técnicos e a extrema habilidade da diretọra na utilização da linguagem cinematográfica, o documentário se mantém nos limites de reiterar a ideologia filmada, associado a ela.

Deduzir todo o Socialismo soviético de um filme seria temerário. Mas não podemos deixar de salientar que esse mesmo filme foi possível dentro daquele Socialismo e foi realizado por artistas socialistas, capazes de incluir tensões e angústias políticas daquele momento em sua obra. A equiparação desse regime ao Nazismo, portanto, se revela, ao menos, inadequada.

\section{Fichas Técnicas de Filmes Referidos:}

Outubro - Dez dias que abalaram o mundo (URSS). 1927. Direção: S. Eisenstein e G. Alexandrov. Produção: Sovkino. Roteiro: S. Eisenstein e G. Alexandrov, a partir do livro 10 dias que abalaram o mundo, de John Reed. Fotografia: E. Tisse e G. Popov. Cenografia: V. Kovriguine. Música: Edmund Meisel. Assistentes de direção: M. Strauch, M. Gomorove I. Trauberg. Elenco: Nikandrov (Lênin), Vladimir Popov (Kerenski), B. Livanov (Terechtchenko), E. Tisse, soldados, camponeses e outros sujeitos populares. 74 minutos. Preto e branco.

O triunfo da vontade (Alemanha). 1935. Direção: Leni Riefenstahl. Produção: Leni Riefehnstal. Montagem: Leni Riefenstahl. Argumento: Leni Riefenstahl e Walter Ruttmann. Música: Herbert Windt. Efeitos especiais: Ernst Kunstmann. Câmera: Sepp Algeier, Karlç Attenberger, Werner Bohne, Walter Frentz, Hans Gottschalk, Werner Hundhausen, Herbert Kebelmann, Albert Kling, Franz Koch, Herbert Kutschbah, Paul Lieberenz, Vlada Majic, Richard Nickel, Walter Himl, Arthur Schwertfeger, Károly Vass, Franz Weymahyr, Siegfried Weimann, Karl Wellert e Wiele Zielke. Aparições: Adolf Hitler, Martin Bormann, Joseph Goebbels, Hermann Goering, Rudolph Hess, Reinhardt Henrich, Henrich Himmler, Alfred Rosenberg e Julius Streicher. 114 minutos. Preto e branco

Blade Runner - O Caçador de Andróides (EEUU), 1981. Direção: Ridley Scott. Roteiro: Hampton Fanches e David Peoples, baseado em novela de Philip Dick. Diretor de Fotografia: Jordan Cronenweth. Efeitos Visuais: Douglas Trumbull. 
Música: Vangelis. Elenco: Harrisson Ford, Sean Young, Rutger Hauer, Edward James Olmos, Daryl Hannah. 118 minutos. Cores.

Gilda (EEUU), 1946. Direção: Charles Vidor. Roteiro: Jo Eisinger e Marion Parsonnet, baseado em estória de E.A. Ellington. Fotografia: Rudolph Mate. Produção: Virginia Van Upp. Elenco: Rita Hayworth (Gilda), Glenn Ford (Johnny Farrell / Narrador), George Macready (Ballin Mundson), Joseph Calleia (Detetive Maurice Obregon), Steven Geray (Tio Pio), Joe Sawyer (Casey), Gerald Mohr (Capitão Delgado), Robert E. Scott (Gabe Evans) e Donald Douglas (Thomas Langford. 110 minutos. Preto e branco.

Psicose (Eeut),.1960. 1960. Produção: Shamley Productions. Distribuição:Paramount Pictures. Direção: Alfred Hitchcock. Roteiro:Joseph Stefano, baseado em livro de Robert Bloch. Produção:Alfred Hitchcock. Música:Bernard Herrmann. Fotografia:John L. Russell. Direção de Arte:Robert Clatworthy e Joseph Hurley. Figurino: Helen Colvig e Rita Riggs. Edição: George Tomasini. Elenco: Anthony Perkins (Norman Bates), Janet Leigh (Marion Crane), Vera Miles (Lila Crane), John Gavin (Sam Loomis), Martin Balsam (Milton Arbogast), John McIntire (Xerife Chambers), Simon Oakland (Dr. Richmond), Vaughn Taylor (George Lowery), Frank Albertson (Tom Cassidy), Lurene Tuttle (Sra. Chambers) e Patricia Hitchcock (Caroline). 109 minutos. Preto e branco.

\section{Referências}

ARENDT, Hannah. Origens do totalitarismo. Tradução de Roberto Raposo. São Paulo: Cia. das Letras, 1989

BARTHES, Roland. Aula. Tradução e apresentação de Leyla Perrone Moysés. São Paulo: Cultrix, 1980.

BENJAMIN, Walter. "A obra de arte na era de sua reprodutibilidade técnica", in: Magia e técnica, arte e política. Tradução de Sérgio Paulo Rouanet. São Paulo: Brasiliense, 1994, p.165/196.

DIEHL, Paula. Propaganda e persuasão na Alemanha nazista. São Paulo: Annablume, 1996. 
GIESEN, Rolf. Nazi propaganda films: a history and filmography. Jefferson: McFarland, 2003.

SAIGADO, Sebastião. Terra. São Paulo: Cia. das Letras, 1997.

\section{Cinema and History Teaching: Propaganda and critics in October and Triumph of the will.}

\section{ABSTRACT}

This article discusses the movies October (1927) by Serguei Eisenstein and Grigory Alexandrov, and Triumph of the Will (1935) by Leni Riefenstahl. The text highlights the different connections between these movies, and the political regime of the country in which they were produced. Eisenstein and Alexandrov celebrate the Revolution of 1917, but maintain the narrative tensions over the significance of idols for politics. Riefenstahl restates Nazi ideals and defines his movie as propaganda. The two movies can help with the debates over the concept of Totalitarianism during History lessons.

Key-words: October (the movie) - The triumph of the will - Serguei Eisenstein 